J. Med. Microbiol. - Vol. 26 (1988), 307-311

(C) 1988 The Pathological Society of Great Britain and Ireland

\title{
Non-immune immunoglobulin binding by "Haemophilus somnus"
}

\author{
P. R. WIDDERS, J. W. SMITH, M. YARNALL, T. C. MCGUIRE and L. B. CORBEIL* \\ Department of Veterinary Microbiology and Pathology, Washington State University, Pullman, Washington \\ 99164-7040. USA
}

\begin{abstract}
Summary. In-vitro culture of Haemophilus somnus in liquid or solid media supplemented with bovine blood or serum resulted in non-immune binding of immunoglobulin (Ig) by the organism. This binding was independent of the antigencombining site of the Ig molecule, since binding of an IgG preparation specific for the hapten dinitrophenol was unaffected by the presence of the homologous antigen. Quantitative comparison of the binding of Ig fragments Fab and Fc demonstrated that the non-immune binding occurred in the $\mathrm{Fc}$ region of bovine $\mathrm{IgG}$. The isotypes of Ig that became bound to $H$. somnus included both bovine $\mathrm{IgG}$ subclasses $\left(\operatorname{IgG}_{1}\right.$ and $\mathrm{IgG}_{2}$ ), which were bound equally, and bovine IgM.
\end{abstract}

\section{Introduction}

Non-immune binding of immunoglobulin (Ig) has been described for staphylococci (Dossett et al., 1969) and streptococci (Kronvall, 1973; Reis et al., 1984; Yarnall and Boyle, 1986), and reported to occur on the surface of other micro-organisms including Brucella abortus (Nielsen et al., 1981b), Taylorella equigenitalis (Widders et al., 1985), mycoplasmas (Williams et al., 1970), Schistosoma mansoni (Torpier et al., 1979), trypanosomes (Ferreira de Miranda-Santos and Campos-Neto, 1981) and Herpes simplex virus (Dowler and Veltri, 1984).

This study describes an Ig binding mechanism on the surface of the gram-negative bacterium "Haemophilus somnus". This organism is a systemic and mucosal pathogen of cattle, causing diseases of the central nervous system, respiratory tract, and reproductive tract (Humphrey and Stephens, 1983). Also, it persists on the respiratory and genital mucosae of apparently normal cattle (Slee and Stephens, 1985). The purpose of this study was to investigate the basis for binding of bovine Ig to the surface of $\boldsymbol{H}$. somnus grown in serum-supplemented media, and to determine the nature of this binding in the context of its possible role in bacterial pathogenicity.

Received 14 Oct. 1987; revised version accepted 11 Jan. 1988.

* Present address: University of California, UCSD Medical Center, San Diego, California 92103, USA.

\section{Materials and methods}

\section{H. somnus strains}

The strains stored at $-70^{\circ} \mathrm{C}$ were as follows: no. 8025 , a laboratory strain isolated from a case of thromboembolic meningoencephalitis; no. 649-4, from an aborted bovine fetus used experimentally to reproduce abortion (Widders et al., 1986); and no. 2336, from a case of bovine pneumonia and used experimentally to reproduce pneumonia (Gogolewski et al., 1987). Bacteria were cultured on plates of Columbia blood agar base with bovine blood or fetal bovine serum $10 \%$, or in brain heart infusion broth supplemented with Tris $0 \cdot 1 \%$ and thiamine monophosphate $1 \mu \mathrm{g} / \mathrm{ml}$.

Bacteria for use as coating antigen in the ELISA were washed three times in isotonic saline containing formalin $1 \%$ by centrifugation for $10 \mathrm{~min}$ at $10000 \mathrm{~g}$. Plate-grown bacteria were suspended in $0.1 \mathrm{M}$ phosphate-buffered

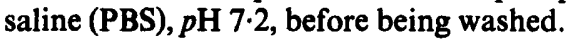

\section{Immunoglobulins}

Bovine $\operatorname{IgG}_{1}, \mathrm{IgG}_{2}$ and $\mathrm{IgM}$ specific for the hapten dinitrophenol (DNP) was a gift from Dr Tom Besser, College of Veterinary Medicine, Washington State University. These antibody preparations were purified from normal bovine serum as previously described (McGuire et al., 1979). Briefly, specific antibody was affinity-purified from normal bovine serum on a column of DNP-lysine-agarose. The Ig preparation was chromatographed on Biogel A 1.5 (Bio-Rad Laboratories, Richmond, CA, USA) to obtain IgM. The IgG subclasses $\left(\mathrm{IG}_{1}\right.$ and $\left.\mathrm{IgG}_{2}\right)$ were isolated by ion-exchange chromatography on DEAE-cellulose equilibrated with $0.005 \mathrm{M}$ 
sodium phosphate buffer, $p \mathrm{H} \mathrm{8 \cdot 0.} \mathrm{Unbound} \mathrm{Ig} \mathrm{was} \mathrm{IgG}_{2}$. $\mathrm{IgG}_{1}$ fractions eluting with a linear $\mathrm{NaCl}$ gradient were pooled, equilibrated with $0.001 \mathrm{M}$ sodium phosphate, $p \mathrm{H}$ 7.5 , containing glycine $0.5 \%$ and applied to an isoelectric focusing column. Those $\operatorname{IgG}_{1}$ fractions at the lower end of the $p \mathrm{H}$ gradient $\left(\mathrm{pH}\right.$ 6-8) lacked $\mathrm{IgG}_{2}$.

Polyspecific $\operatorname{IgG}_{2}$ and $\mathrm{IgG}\left(\mathrm{IgG}_{1}+\mathrm{IgG}_{2}\right)$ were similarly purified from normal bovine serum by ion-exchange chromatography on DEAE-cellulose.

The purity of the immunoglobulin preparations was monitored by immunoelectrophoresis developed with rabbit anti-bovine whole serum (fig. 1) and by enzymelinked immunosorbent assay (ELISA) with monoclonal antibodies specific for bovine $\mathrm{IgG}_{1}, \mathrm{IgG}_{2}, \mathrm{IgA}$ (supplied by Dr A. Guidry, USDA, Beltsville, MD, USA) and IgM (supplied by Dr W. Davis, Washington State University) as described below. Contaminating serum proteins and other Ig isotypes were undetectable in the IgG preparations by immunoelectrophoresis and ELISA respectively. The IgM antibody specific for DNP produced a single precipitin line on immunoelectrophoresis (data not shown) but a minor $\mathrm{IgG}_{1}$ contaminant was detectable by ELISA (data not shown).

Polyspecific $\operatorname{IgG}\left(\mathrm{IgG}_{1}\right.$ and $\left.\mathrm{IgG}_{2}\right)$ was digested with papain (Porter, 1950) for $6 \mathrm{~h}$. The Fab and Fc fragments were isolated by ion-exchange chromatography on DEAE-cellulose equilibrated with $0.005 \mathrm{M}$ sodium phosphate, $p \mathrm{H} \mathrm{8.0.} \mathrm{Fab} \mathrm{was} \mathrm{not} \mathrm{bound} \mathrm{to} \mathrm{the} \mathrm{column} \mathrm{in}$ starting buffer. Undigested IgG and some Fc was eluted with $0.05 \mathrm{M}$ sodium phosphate, $p \mathrm{H} 8 \cdot 0$. Fc was eluted with $0 \cdot 1 \mathrm{M}$ sodium phosphate, $p \mathrm{H} 8 \cdot 0$, with $1 \cdot 0 \mathrm{M} \mathrm{NaCl}$. Purity of the fractions was monitored by immunoelectrophoresis (fig. 1).

\section{ELISA}

To test for Ig purity and Ig binding to bacteria, the Ig preparations $(10 \mu \mathrm{g} / \mathrm{ml})$ or formalinised bacteria $(22 \%$ transmission at $610 \mathrm{~nm}$ ) were used to coat the wells of a polystyrene microelisa plate (Costar) by incubation in PBS with $0.02 \mathrm{M} \mathrm{MgCl}_{2}$ overnight at $4^{\circ} \mathrm{C}$. Antigen concentrations that gave optimal coating were determined by titrating antigen in coating buffer. Omission of coating antigen resulted in only background readings in the ELISA.

Monoclonal antibodies used to monitor Ig purity were diluted in PBS with Tween $200.05 \%$. Ig preparations used to measure binding to bacteria were diluted in PBS with Tween $200.05 \%$ containing polyvinyl pyrrolidone $2 \%$ and ovalbumin $0.2 \%$. These solutions were incubated with antigen-coated plates for $1 \mathrm{~h}$ at $37^{\circ} \mathrm{C}$.

Binding of bovine IgG to bacteria was measured by means of peroxidase-conjugated rabbit-antibovine IgG (heavy and light chain specific; Cappell Worthington). Binding of IgM was measured with IgM monoclonal antibody. Monoclonal binding in ELISA was measured with peroxidase-conjugated goat-antimurine IgG (Kirkegaard and Perry Laboratories). Reactions were developed with $\mathrm{H}_{2} \mathrm{O}_{2}$ in 5 aminosalicylic acid and plates were read in the dual wavelength mode at 490 and $630 \mathrm{~nm}$ in an ELISA reader. End-points for ELISA titrations were determined by calculating the protein concentration that resulted in an optical density (OD) of $0.20(3 \times$ background $O D)$.

\section{Results}

In developing an ELISA to measure bovine antibody specific for $H$. somnus, high background ODs were encountered when the coating antigen consisted of bacteria grown in bovine serumsupplemented media. This high background was seen with both plate- and broth-grown bacteria (fig. 2 ), and was eliminated by growing the organism in media deficient in bovine Ig (Columbia blood agar

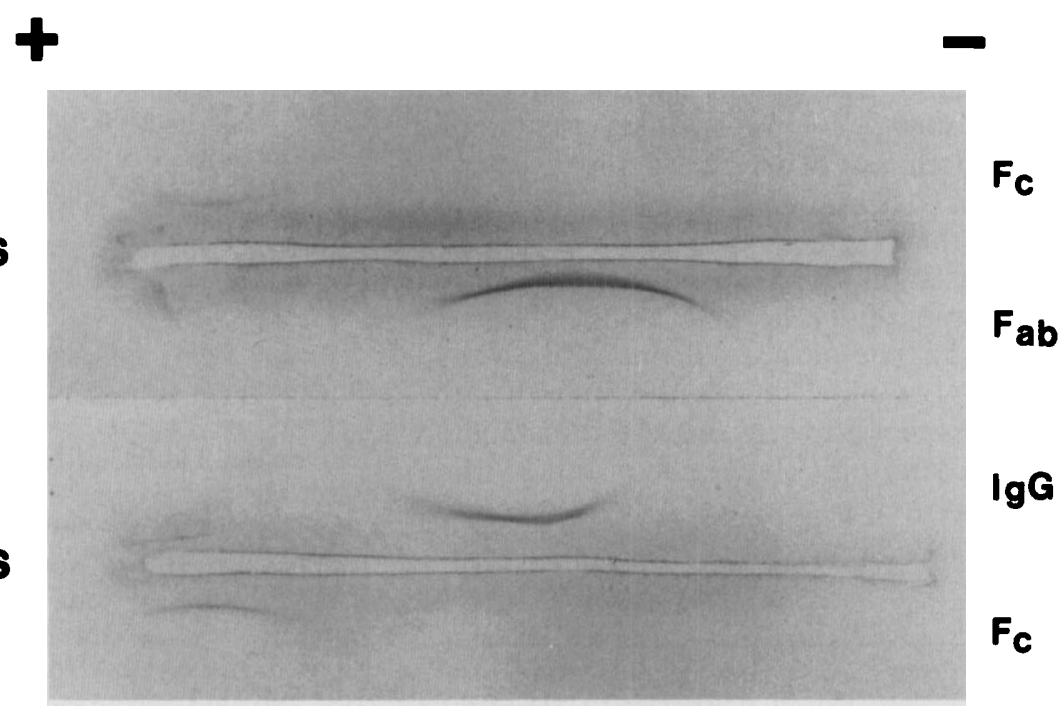

Fig. 1. Immunoelectrophoresis of bovine $\mathrm{IgG}, \mathrm{Fab}$ and $\mathrm{Fc}$ fragments developed with antiserum to bovine whole serum (WS). 


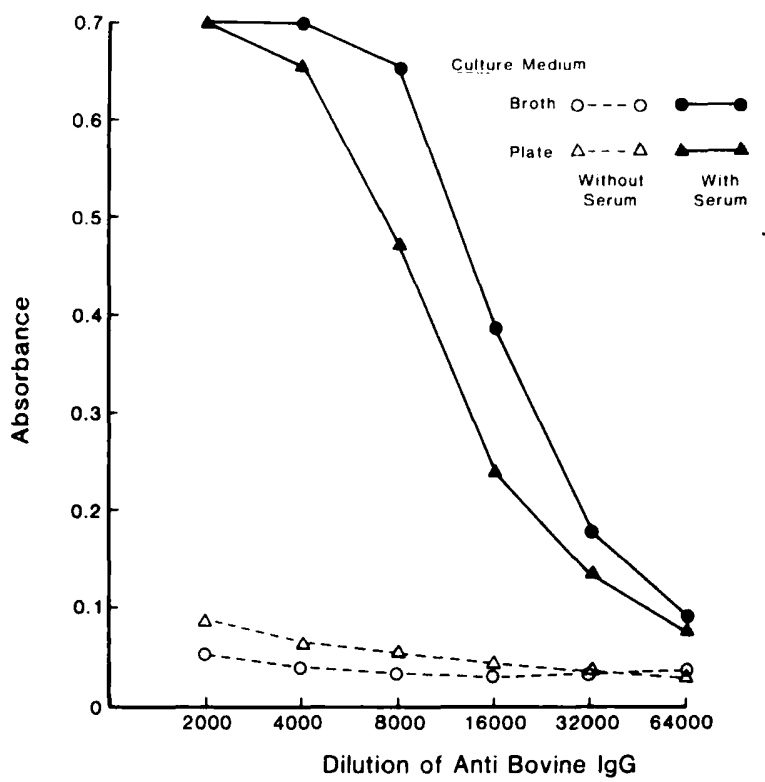

Fig. 2. IgG bound by $\boldsymbol{H}$. sommus grown in liquid or solid media with or without a $10 \%$ supplement of heat-inactivated normal bovine serum.

with fetal bovine serum instead of bovine blood, or liquid medium with no serum supplement; fig. 2). Clearly, growth of $H$. somnus in culture media containing bovine Ig resulted in Ig binding to the bacterial cell surface.

In an attempt to clarify the role of antibody specificity in the binding of $\mathrm{Ig}$ to $H$. somnus, the binding of monospecific (anti-DNP) and polyspecific Ig preparations was titrated by the ELISA (table) with antigen consisting of bacteria grown in serum-free medium. There was no difference in

Table . Ig and Ig-fragment binding to $H$. somnus

\begin{tabular}{lc}
\hline Immunoglobulin & End-point* $^{*}$ \\
\hline Anti DNP IgG & 38 \\
Anti DNP IgG & 38 \\
Polyspecific IgG & 2 \\
Anti DNP IgM & 19 \\
Fab & $6 \dagger$ \\
Fc & 100
\end{tabular}

\footnotetext{
* The end-point for binding of whole Ig preparations is expressed as the minimal Ig concentration $(\mu \mathrm{g} / \mathrm{ml})$ at which binding could be detected.

† Binding of the Ig fragments was corrected for differential recognition of the Fab and Fc fragment by anti-bovine IgG (see text). Accordingly, Fc binding is set at 100 , with Fab binding at $6 \%$ the level of Fc binding.
}

binding of $\operatorname{lgG}_{1}$ and $\operatorname{IgG}_{2}$ anti-DNP antibody to $H$. somnus, binding being detectable in solutions of $38 \mu \mathrm{g} / \mathrm{ml}$ (table). IgM also was bound in this assay (table), with an end-point at $19 \mu \mathrm{g} / \mathrm{ml}$. IgG binding to $H$. somnus was measured in a direct ELISA with peroxidase-conjugated antiserum to bovine IgG (heavy and light chain specific). IgM binding was measured in an indirect ELISA with monoclonal antibovine IgM followed by peroxidase-conjugated antimurine IgG. Since different amplification steps and different antisera were used to measure IgG binding and IgM binding, quantitative comparison of IgG and IgM binding is not possible.

Binding of polyspecific $\mathrm{IgG}_{2}$ was recorded with an end-point to binding at $2 \cdot 3 \mu \mathrm{g} / \mathrm{ml}$ as compared with an end-point of $38 \mu \mathrm{g} / \mathrm{ml}$ for anti-DNP IgG. To define the role of the antigen binding sites of Ig in mediating binding to $H$. somnus, the effect of DNP on binding of antibody specific for DNP was investigated in ELISA. With coating antigens consisting of DNP-BSA (bovine serum albumin) or H. somnus, binding of $\operatorname{IgG}_{2}$ anti-DNP was titrated in the presence of BSA, or DNP-BSA (fig. 3). When DNP-BSA was used as the coating antigen, Ig binding was inhibited by soluble DNP-BSA, but not by BSA (fig. 3). In contrast, with $H$. somnus as

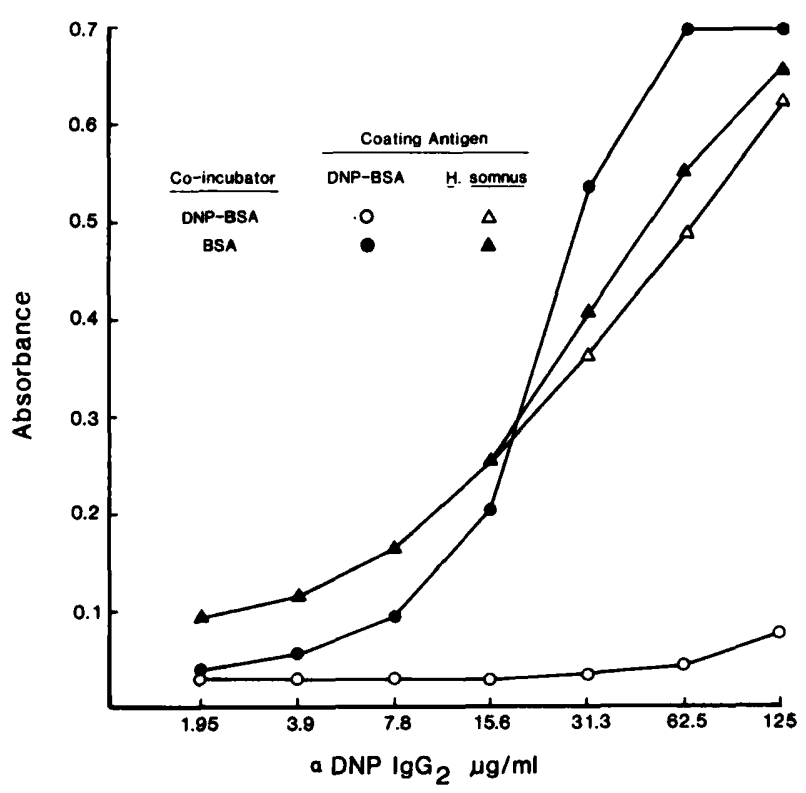

Fig. 3. Participation of the antigen binding site of anti-DNP IgG in binding to $H$. sommus. Anti-DNP IgG was titrated in the presence of DNP-BSA or BSA in the wells of a microtitration plate coated with DNP-BSA or $\boldsymbol{H}$. somnus. Binding of anti-DNP IgG to DNP-BSA was inhibited by co-incubation with DNPBSA but not BSA, while binding of anti-DNP IgG to $H$. somnus was not inhibited by DNP-BSA or BSA. 
coating antigen, Ig binding was comparable in solutions of BSA or DNP-BSA (fig. 3).

Relative binding of the Fab and Fc fragments of bovine IgG was estimated by titrating binding to $H$. somnus in ELISA. The peroxidase-conjugated rabbit-antibovine Ig used to measure binding did not recognise the $\mathrm{Ig}$ fragments equally, and a correction for this bias was therefore necessary. This was effected by directly coating the microtitration wells with decreasing concentrations of the $\mathrm{Ig}$ fragments, and calculating an endpoint for binding of the conjugated antibovine $\mathrm{Ig}$. With $\mathrm{Fc}$ endpoints set at 1 , the relative binding of the $\mathrm{Ig}$ fragments, Fc:Fab, was 1:0.6 for binding to $H$. somnus, and 1:10 when coated directly on to the microtitration wells. Therefore, after correcting for differences in recognition of the Ig fragments by the conjugated antiserum, Fab fragment was bound to $H$. somnus at only $6 \%$ of the level of Fc binding.

To monitor growth-phase variation in Ig-binding activity, a bacterial culture in serum-free liquid medium was sampled hourly from 0 to $9 \mathrm{~h}$ and at $24 \mathrm{~h}$. The washed bacteria were used as coating antigen in an ELISA to measure binding of antiDNP $\mathrm{IgG}_{2}$. There was minimal variation in the end-point of Ig binding, from the lag phase, through $\log$ phase, to the stationary phase of growth.

\section{Discussion}

This study identified a non-immune Ig binding mechanism on the surface of $H$. somnus. Ig binding was detected in the presence of a 50-fold excess of ovalbumin and a 500-fold excess of polyvinyl pyrrolidone, suggesting that binding was specific for Ig. Subsequent studies have identified bacterial surface proteins with $\mathrm{Fc}$ binding activity and have characterised the species-specificity of Ig binding (Yarnall et al., in press).

Antibody specific for the hapten DNP became bound to $H$. somnus in the ELISA, and this binding was unaffected by the presence of the homologous antigen, DNP-BSA. Thus, the antigen combining sites of the Ig molecule play no part in this interaction. Binding of polyspecific IgG was greater than that for monospecific (anti-DNP) IgG. This difference in binding is likely to have been due to natural antibody in the polyspecific Ig preparation purified from normal bovine serum. Quantitative comparison of $\mathrm{Fab}$ and $\mathrm{Fc}$ binding by $H$. sommus suggests that the specificity of the non-immune binding mechanism is directed towards a site in the $\mathrm{Fc}$ region of bovine $\mathrm{IgG}$, since $\mathrm{Fab}$ was bound to $H$. somnus at only $6 \%$ of the binding of Fc (table).
This level of Fab binding probably reflects the presence of cross-reactive antibody specific for $\boldsymbol{H}$. somnus in normal bovine serum.

The Fc-directed binding by $H$. somnus parallels the reactivity of similar binding mechanisms described for Staphylococcus aureus, Streptococcus spp., Schistosoma mansoni, trypanosomes, and Herpes simplex virus. In the present study, both bovine IgG and IgM were bound by a non-immune mechanism, since both IgG and IgM antibody specific for DNP were bound to the surface of $H$. somnus. It is unclear, from the present study, whether IgG and IgM binding to $H$. somnus is mediated by the same or distinct bacterial surface components. Fc-specific, non-immune binding of bovine IgM has also been reported for $B$. abortus (Nielsen et al., 1981b), but the binding mechanism in this instance was specific for a subpopulation of bovine IgM molecules. Similarly, a proportion of bovine sera displayed ethylenediaminetetraacetic acid (EDTA)-labile binding of $\mathrm{IgG}_{1}$ to $B$. abortus (Nielsen et al., 1981a). The role of the Fc and Fab fragments in binding was not investigated for this isotype.

In the present study, the assays used to quantitate IgG and IgM binding employed different antisera and different amplification steps, preventing a quantitative comparison of IgG and IgM binding. However, there was no difference in reactivity between the bovine IgG subclasses (table), suggesting that the Ig-binding mechanism of $\boldsymbol{H}$. somnus recognises a class-specific rather than a subclassspecific determinant on bovine Ig. In comparison, type III streptococcal-Fc receptors bind both bovine $\mathrm{IgG}_{1}$ and $\mathrm{IgG}_{2}$ (Reis et al., 1983), and protein $\mathrm{A}$ of $S$. aureus binds well to bovine $\mathrm{IgG}_{2}$ but only weakly to $\operatorname{IgG}_{1}$ (Goudswaard et al., 1978).

Non-immune Ig binding by microbial pathogens probably represents a specific adaptation for evasion of host effector functions. Non-immune $\mathrm{Ig}$ binding has been associated with virulence in schistosomes (Torpier et al., 1979) and trypanosomes (Ferreira de Miranda-Santos and CamposNeto, 1981). Ig binding by staphylococcal protein A has been associated with a reduction in phagocytosis (Dossett et al., 1969) by an effect on Fcmediated interaction with phagocytes (Peterson $e t$ al., 1977). Similarly, binding of fibrinogen by the $\mathbf{M}$ protein of group A streptococci resulted in limited deposition of complement on the bacterial cell surface (Whitnack et al., 1984). Non-immune binding of $\mathrm{Ig}$ might function similarly to mask bacterial surface structures targeted by specific antibody or complement, thereby reducing opsonisation and susceptibility to killing and phagocyto- 
sis. The significance of non-immune Ig binding as a virulence determinant of $H$. somnus warrants further investigation in view of the organism's (1) resistance to complement-mediated killing, (2) persistence at mucosal surfaces, (3) capacity to

\section{REFERENCES}

Dossett J H, Kronvall G, Williams R C, Quie P G 1969 Antiphagocytic effects of Staphylococcal protein A. Journal of Immunology 103: 1405-1410.

Dowler K W, Veltri R W 1984 In vitro neutralization of HSV2: Inhibition by binding of normal IgG and purified Fc to virion Fc receptor (FcR). Journal of Medical Virology 13: 251-259.

Ferreira de Miranda-Santos I K, Campos-Neto A 1981 Receptor for immunoglobulin Fc on pathogenic but not on nonpathogenic protozoa of the trypanosomatidae. Journal of Experimental Medicine 154: 1732-1742.

Gogolewski R P, Leathers C W, Liggitt H D, Corbeil L B 1987 Experimental Haemophilus somnus pneumonia in calves and immunoperoxidase localization of bacteria. Veterinary Pathology 24: 250-256.

Goudswaard J, Van der Donk J A, Noordzij A, van Dam R H, Vaerman J P 1978 Protein A reactivity of various mammalian immunoglobulins. Scandinavian Journal of Immunology 8: 21-28.

Humphrey J D, Stephens L R 1983 Haemophilus somnus: a review. Veterinary Bulletin 53: 987-1004.

Kronvall G 1973 A surface component in group A, C and G streptococci with non-immune reactivity for Immunoglobulin G. Journal of Immunology 111 : 1401-1406.

McGuire T C, Musoke A J, Kurtti T 1979 Functional properties of bovine $\mathrm{IgG}_{1}$ and $\operatorname{lgG}_{2}$ : Interaction with complement, macrophages, neutrophils and skin. Immunology 38: 249256.

Nielsen K, Duncan J R, Stemshorn B, Ruckerbauer G $1981 a$ Relationship of humoral factors (antibody and complement) to immune responsiveness, resistance and diagnostic serology. Advances in Experimental Medicine and Biology 137: 367-389.

Nielsen K, Stilwell K, Stemshorn B, Duncan R $1981 b$ Ethylenediaminetetraacetic acid (disodium salt)-labile bovine immunoglobulin M Fc binding to Brucella abortus: A cause evade host effector functions in vivo, and (4) ability to cause a range of bovine infections.

The technical assistance of Susan Dowling is gratefully acknowledged.

of nonspecific agglutination. Journal of Clinical Microbiology 14: 32-38.

Peterson P K, Verhoef J, Sabath L D, Quie PG 1977 Effect of protein $\mathrm{A}$ on Staphylococcal opsonization. Infection and Immunity $15:$ : 760-764.

Porter R R 1950 Use of 1:2:4-fluorodinitrobenzene in studies of protein structure. Methods in Medical Research 3: 256-271.

Reis K J, Boyle M D P, Ayoub E M 1984 Identification of distinct Fc-receptor molecules on steptococci and staphylococci. Journal of Clinical and Laboratory Immunology 13: 75-80.

Slee K J, Stephens L R 1985 Selective medium for isolation of Haemophilus somnus from cattle and sheep. Veterinary Record 116: 215-217.

Torpier G, Capron A, Ouaissi M A 1979 Receptor for IgG(Fc) and human $\beta_{2}$-microglobulin on $S$. mansoni schistosomula. Nature 278: 447-449.

Whitnack E, Dale J B, Beachey E H 1984 Common protective antigens of group A streptococcal $\mathbf{M}$ proteins masked by fibrinogen. Journal of Experimental Medicine 159: 12011212.

Widders P R, Stokes C R, Newby T J, Bourne F J 1985 Nonimmune binding of equine immunoglobulin by the causative organism of contagious equine metritis (Taylorella equigenitalis). Infection and Immunity 48: 417-421.

Widders P R, Paisley L G, Gogolewski R P, Evermann J F, Smith J W, Corbeil L B 1986 Experimental abortion and the systemic immune response to Haemophilus somnus in cattle. Infection and Immunity 54: 555-560.

Williams M H, Brostoff J, Roitt I M 1970 Possible role of Mycoplasma fermentans in pathogenesis of rheumatoid arthritis. Lancet 2: 277-280.

Yarnall M, Boyle M D P 1986 Isolation and partial characterisation of a type II Fc receptor from a group A steptococcus. Molecular and Cellular Biochemistry 70: 57-66.

Yarnall M, Widders P R, Corbeil L B Isolation and characterisation of Fc receptors from Haemophilus somnus. Scandinavian Journal of Immunology. In press. 